\title{
Theory and Practice Research for Curriculum Resources Development and Utilization for Immunology Basics and Pathogen Biology
}

\author{
Chunjuan Fang \\ School of nursing, Jiangxi University of Technology
}

Keywords: Curriculum Resources; Development and Utilization; Immunology

\begin{abstract}
Curriculum Resources has received continuous attention in a new round of curriculum reform of elementary education. Effective development and rational utilization of curriculum resources has important significance for changing students' passive learning style, transforming the traditional mode of teaching and the mobilization of the subjectivity of students. Therefore, the rational development and utilization of curriculum resources has become an important research topic since the new curriculum reform. This paper presents a number of issues about the curriculum resource development and utilization of Immunology Basics and Pathogen Biology, including development focus, developing ways and impact to students' learning mode and knowledge mastery and so on after development, as well as whether it helps train students' practical ability and creative spirit and so on. We are trying to study and discuss these issues, find ways and means of rational and efficient development and utilization of curriculum resources in the context of the new curriculum to promote the development and use of Immunology Basics and Pathogen Biology and other curriculum resources. Curriculum resources refer to available resources in the entire curriculum development process, including curriculum design, implementation and evaluation and so on, which has such characteristics as diversification, multi-quality and flexibility.
\end{abstract}

\section{Introduction}

With the formulation of 21st Century Education Revitalization Action Plan by the State Council in 1999 and the successful holding of the third National Education Conference, a new round of curriculum reform of elementary education has regarded the process of promoting the quality education as the core, in order to change students' learning mode. In this curriculum reform, the concept of curriculum resource is explicitly put forward; curriculum resources issues have received unprecedented attention.

Development and utilization of curriculum resources help expand the scope of school education, strengthen the association between school education in educational content and each system of society; help establish great education concept for school in order to handle the relationship between school education and lifelong education; development and utilization of curriculum resources can make teaching surpass narrow educational content and integrate life and experiences of teachers and students into the teaching process, which is of great significance for changing the traditional mode of education centered on teaching materials, transforming course function, changing students' learning mode and so on. In addition, during the process of development and utilization of curriculum resources, educational level and professional skills of teachers can be improved, which can also open 
the teachers' vision, promote teachers to change their education ideas and stimulate creativity wisdom, which is very important for teachers to improve and develop their own quality.

Curriculum resources usually include explicit curriculum resources and implicit curriculum resources. Explicit curriculum resources are tangible, which can better access to the developer's sight, and has become the developer's main development target. The implicit curriculum resources are intangible, such as knowledge, skills, experience, activity patterns, attitudes and values implicit in the curriculum, it is easy to be overlooked by developers due to hidden features. In the present case, compared with explicit curriculum resources, teachers have less knowledge of the implicit curriculum resources, and the consciousness of developing and utilizing curriculum resources is much weaker. In addition, from the perspective of development constraints, explicit curriculum resources development is primarily influenced by funding, and the implicit curriculum resource development is primarily influenced by capacity. From this perspective, implicit curriculum resource development is more difficult than explicit curriculum resources development. Thus, practice research for implicit curriculum resources development and utilization is less than that for explicit curriculum resources development and utilization. And monographic study for curriculum resources of Immunology Basics and Pathogen Biology is a blank.

This paper presents a number of issues about curriculum resources of Immunology Basics and Pathogen Biology, including development focus, developing ways and impact to students' learning mode and knowledge mastery and so on after development, as well as whether it helps train students' practical ability and creative spirit and so on. We are trying to study and discuss these issues, find ways and means of rational and efficient development and utilization of curriculum resources in the context of the new curriculum to promote the development and use of Immunology Basics and Pathogen Biology and other curriculum resources. Curriculum resources refer to available resources in the entire curriculum development process, including curriculum design, implementation and evaluation and so on, which has such characteristics as diversification, multi-quality and flexibility. Curriculum resources of Immunology Basics and Pathogen Biology in technical secondary school should be under the guidance of professional training objectives, following the educational principle, adaptability principle, the principle of priority, people-oriented principles, to determine the appropriate development of content, select the appropriate method way and develop and utilize rationally and efficiently.

\section{Theoretical Foundation for Curriculum Resources Development and Utilization}

Curriculum and curriculum theory. Curriculum is the most popular educational term in the education field, the word "curriculum" has appeared in China's Song dynasty, curriculum at that time refers to the learning scope and process. With the continuous development of society, the connotation and extension of curriculum are constantly changing, especially after the 1960s, the meaning of curriculum is boldly expanded, the curriculum contains not only the subject itself, but also the non-curriculum experience in school life, the course is no longer seen as a one-way knowledge transfer process, but a two-way flow practice. Although different scholars has different explanations for curriculum, but it is believed that the teaching subjects, academic structure and process should be regarded as the basic content of the course. In Contemporary Education (revised edition) edited by Professor Yuan Zhenguo, the explanation for curriculum is as follows: curriculum is a developing concept, which is to achieve the aims of education at all levels and is the sum of teaching purpose, content, scope, components and processes, including all the content for the overall 
development of students personality. This concept is more representative. From this concept, it is easy to see that the coverage of the curriculum is relatively broad, not only includes the subject itself, but also includes a variety of factors related to teaching. Universality of curriculum concept determines that education resources are also diversified and rich.

Important representative of the modern curriculum theory, Taylor has summed up the curriculum theory from the four basic problems in Basic Principles of Curriculum and Instruction, including the educational goals, educational content, how to teach, how to assess the problem, and there are three factors to be considered to determine education target, namely the subject logic, students' psychological development logic and social requirements, since different people emphasize the extent of these three factors to different levels at different times, which constitutes different ideas or different curriculum genres. There are three more representative genres, namely, subject-centered curriculum theory, humanistic curriculum theory, curriculum theory of social reconstruction doctrine; as for subject-centered curriculum theory, the school curriculum should be classified on the basis of discipline, and the subject teaching should be regarded as the core, in order to grasp basic knowledge, basic rules and appropriate skills. As for humanistic curriculum theory, curriculum theory should be helpful to human dignity, and human potential should be realized and developed in the educational process, emphasizing that curriculum should be determined according to the psychological development characteristics and psychological development requirements of children. Social reconstruction doctrine curriculum theory emphasizes the role of social constraints on education, advocating that educational purposes and curriculum activities should be determined in accordance with the needs of society and emphasizing the role of moral education and the social authority.

Curriculum property determines the diversified curriculum resources, teachers determine the type and distribution of curriculum resources that can be developed and design the development processes and procedures and evaluate development effect through analysis for curriculum target and content. It is also in the process of development and utilization of curriculum resources, the teacher's knowledge structure has been optimized, capacity has been developed and the level of awareness for curriculum resources can be improved, so as to form a scientific and effective curriculum resource view.

Learning theory. Constructivism learning theory:

According to constructivist learning theory, how much knowledge we can get depends on the ability of learners to construct knowledge based on their own experience, which doesn't depend on how students remember and how much knowledge teachers have taught. Therefore, constructivism advocates that learners should be regarded as center under the guidance of teachers. It requires teachers to stimulate student interest in the teaching process, helping students develop motivation. Students should construct meaning of knowledge through exploration in the learning process. In order to make the construction of meaning become more efficient, the teacher can ask the right questions in order to arouse students ' thinking and discussion, trying to deepen the problem in order to deepen students' understanding in the discussion, and inspiring students to discover rules, correct and supplement errors. This can be seen that constructivist learning theory has many similarities with present inquiry-based learning and independent study, which can be used as the theoretical basis of curriculum resources development and utilization.

Humanistic learning theory:

Humanistic learning theory represented by Rogers advocates to understand the psychology from the direct experience and inside feeling, emphasizes human nature, dignity, ideals and interests and 
emphasizes that learning is the process of developing people's potential and realizing human values, which requires students learn happily and creatively. Under the historical background in advocating the development of student's personality, cultivation of the innovation sprit and practical sprit, development and utilization of curriculum resources must be people-centered, development and utilization of any resource must be able to promote student to learn happily and creatively.

\section{Analysis for curriculum resources situation of Immunology Basics and Pathogen Biology}

Explicit curriculum resources. Explicit curriculum resources are tangible resources, including teachers, students, teaching materials, laboratories, libraries, networks, and other resources. The vast majority of these resources have become fixed curriculum resources of Immunology Basics and Pathogen Biology. However, during the process of utilizing these resources, we still have some issues to resolve, following analysis is conducted for several major curriculum resources to identify the existing problems in order to seek for appropriate solutions.

Human resources. Human resources include teachers, students, and education managers. Teachers are the main human resource of teaching and have a direct and important influence. There are significant differences in teachers' ability and development and utilization level of curriculum resources. Some teachers are good at to put their resources appropriately to teaching, and some teachers are not good at applying or apply inappropriately. Some teachers have a solid professional knowledge, and they can use their knowledge resources very well in teaching, but they are not good at understanding students, communicating with students and developing and utilizing their own thinking, experience and emotional resources. As for some teachers, although they are good at expressing their own life experience, attitude towards people and life and so on to the students, which can be regarded as the development and utilization of their own hidden curriculum resource, however, they don't screen and process all these resources, and such resources may even have a negative impact on the development of students.

Literal resources. Teaching materials and syllabus are the main literal resources. Teaching materials have become the most important resource for its integrity and systematicness, which have long been greatly valued. Teaching materials are regarded as the main basis for teaching. No matter how curriculum will conduct reform, teaching materials are always essential resources, and have always been the main curriculum resources, in general, if the preparation of this textbook is scientific and reasonable, but in practice, it also reflects some of its shortcomings, such as the stiff interpretation of certain concepts seem stiff, some of the content in the actual work has been eliminated and the like.

Facility resources. Facility resources include laboratory facilities, library and reading room and so on. Laboratory is the important curriculum resource for Immunology Basics and Pathogen Biology, it is not only a place to learn the knowledge, but also an important place for students to cultivate practical ability and innovation ability. However, due to various reasons such as lack of funds, laboratory facilities are still not complete and unreasonable, and management is also not in place, resulting in some experiments can not be carried out and the quality of the experiment is difficult to guarantee. And there are excessive replication experiments and few inquiry-based experiments. Although the replication experiments help to consolidate knowledge and develop ability to practice, but they are not conducive to the development of students 'creative thinking, and creative thinking is the necessary thinking quality in today's society and the future society, the school should be responsible for training students' creative thinking. Inquiry-based experiments not only can 
train students to identify problems, analyze problems and solve problems, but also are conducive to the development of students' creative thinking, so it is necessary to reduce the replication experiments and add inquiry-based experiments. The course of the experiment is designed to be the discovery process for students, allowing students to experience the fun of discovering and thinking habits of studying problems, so that students can develop creative thinking.

Implicit curriculum resources .Implicit curriculum resources include knowledge, life experience processed by students and teachers and attitude to education and values as well as other resources. These implicit curriculum resources have a direct and important effect for teaching, but it is easily overlooked due to its hidden features, people are lack of awareness of the rational development and utilization. Compared with explicit curriculum resources, it is more important to develop and utilize implicit curriculum resources, and it is quite difficult.

All kinds of teaching materials have its implicit ideological resources. As for Immunology Basics and Pathogen Biology, it seems that the curriculum is the simple addition of immunology, microbiology and parasitological expertise on the surface, and in fact, once we go in depth and we will find a lot of hidden resources that are helpful for emotional culture, ethics education and value formation. However, these resources are often overlooked by many teachers who think that students 'ideological education is the responsibility of class adviser, so such wrong concept leads to the lack of attention to the students' ideological education.

\section{Principles of developing and utilizing the curriculum resources of Immunology Basics and Pathogen Biology}

Combining the characteristics of Immunology Basics and Pathogen Biology and curriculum resource diversity, we are required to follow the following principles in developing and utilizing the curriculum resources of Immunology Basics and Pathogen Biology.

The principle of serving for training objects. Each level of school education has a clear training objective, the guidance of training objective plays an important in the opening of curriculum, and the development of curriculum resources can not be separated from the training objective. Namely, resource development should serve the training objective and teaching. Technical secondary nursing school aims at cultivating practical talents serving the grassroots level, exception for basic health knowledge and skills; they also need to have grassroots spiritual service and the ability to continue learning. Therefore, we must not only teach them the knowledge and skills, but also teach learning methods and truth in life, so that they not only have qualified for their jobs and can master the basic knowledge, basic skills and methods, but also have optimistic attitude towards life, to be a socially responsible, law-abiding citizens. Development of curriculum resources should focus on these goals, the purpose is to improve the overall quality of students, improve students' social adaptability, rather than for the purpose of the examination. If curriculum resources development deviates from the training objectives, we would rather give up.

In favor of independent study. Curriculum reform is to change the function, structure and content of the course in form, its core is to change students' learning style fundamentally. Therefore, curriculum resources development is to enable students to become masters of learning, so that students can develop consciousness, initiative and creativity, and students can change their passive and single learning style, so that a variety of learning styles such as independent learning, practice, exploration, cooperation and so on can be advocated to cultivate the students' sense of cooperation, innovative spirit and practical ability and form correct values, life and world view imperceptibly in 
the process of learning, to enable students to experience the joy of learning and healthy growth in the study. Development of curriculum resources should facilitate the independent learning. To be emphasized, the preparation of teaching materials should be easy to read and understand for students; laboratories construction and development of other network resources should fully consider independent learning.

Adaptability principle. Curriculum resources development should fit in the students' knowledge, ability level and should be compatible with the school environment and social environment in order to be understood and accepted by students, and students will cooperate with the teachers to achieve the desired effect.

Priority principle. There are a variety of curriculum resources, the course objectives and current conditions should be considered in determining resources development, and it is necessary to follow the value priority, economy and time priority principle to screen curriculum resources to achieve appropriate levels of detail and priority.

Educational principle. Inconsistent knowledge capacity development and ideological quality development are quite common whether in university, high school, or elementary school, there are more and more psychological disorders and even criminal cases among young people, which requires us to pay more attention to students' ideological education. The new teaching planning and outline have put forward the students' ideological education goals clearly; therefore, the development of curriculum resources should consider how to develop the ideological education value in addition to acquiring knowledge or mastery of some kind of skill.

People-oriented principle. Modern educational thought emphasizes the dominant position of students, which can fully reflect the consciousness of students in teaching, promote people-oriented (student-centered) spirit, and it is necessary to reflect the student-oriented spirit in the process of development and utilization of curriculum resources. Therefore, no matter what kind of curriculum resources development, the developer should take the following thought into consideration, that is: develop for students- develop to meet the needs of students.

\section{Concrete practice of the curriculum resources of Immunology Basics and Pathogen Biology}

Development of learning activities (preparation of antibody molecules model)

First, based on voluntary participation principles, one third of students (20 people) will participate in this activity, then the students recognize the concept, structure and function and son on of antibodies theoretically through self-study textbook, and then students are required to prepare an antibody molecule model on the basis of understanding teaching materials.

Secondly, the production results will be presented in the classroom, and students are organized to analyze and evaluate all models, identify the best materials, Best Production Award, the Most Exquisite Prize and other awards, and select some works to post in the classroom prominently。

Thirdly, students are allowed to talk about experiences and feelings.

Fourthly, generalization and summarization will be conducted to point out deficiencies and put forward expectations.

Implementing activities provide students with the opportunity to demonstrate ability, which not only helps the students to master the basic structure and function of antibodies, develop student's imagination and aesthetic taste and cultivate operational ability, but also enhances learning interest in immunology and increases the chance of communication, namely, it has multiple purposes. 


\section{Conclusions}

To complete this study, the writer has conducted a lot of work, including the collection of data, analytical thinking, attempting practice and statistical analysis and so on. First, I have collected and read a large variety of theoretical and practical studies on curriculum resources; secondly, I have conducted a comprehensive analysis on curriculum resources of Immunology Basics and Pathogen Biology and put forward suggestions about curriculum resources development and utilization; Finally, I have conducted specific practice on the part of curriculum resources such as multimedia courseware, teaching activities, teaching materials, students' experiences of exploitation. The results prove that the development and utilization of curriculum resources can contribute to improve the teaching effect, contributing to curriculum objectives. But there are also disadvantages, such as how to conduct further systematic and theoretical analysis for curriculum resources.

However, this study presents the problem of curriculum resource construction of a discipline, which itself has great limitations. Because the curriculum reform has proposed is to dilute the sense of discipline, increase comprehensive programs and improve overall quality. Around this idea, curriculum resources should be optimized overall and allocated rationally, which should not only have the thought of small discipline, but also have a sense of large discipline, it is necessary to avoid fragmentation of curriculum resources and to avoid duplication of curriculum resources. Thus, how to conduct further systematic and theoretical analysis for curriculum resources needs further efforts.

\section{References}

[1] Jin Yule, Song Naiqing, Xu Zhonglin, What Will Bring to Teachers from New Teaching Materials- Discussion on New Features of New Materials, Peking University Press, 2002

[2] Hao Deyong, Methodology of the Curriculum Development, Education Science Press, 2000

[3] Liu Xudong, Zhang Ningjuan, Ma Li, School-based Curriculum and Curriculum Resource Development, China Personnel Press, 2003

[4] Wang Zhongli, Lu Jiandang, Evaluation and Resources of the New biological Curriculum, Higher Education Press, 2003

[5] Huang Kexiao, Outline for Vocational and Technical Education Courses, East China Normal University Press, 2001

[6] Wu GangPing, Theoretical Conception of Curriculum Resources, Education and Research, 2001 (9)

[7] Wu GangPing, Reflection and Exploration of Some Issues in the Teaching Reform and Infrastructure Construction, Education and Rresearch, 2002 (1)

[8] Li Jianping, How to Develop Curriculum Resources - Expert Discussion on the Basic Education Curriculum Rreform (of the eight), China's basic education network 20019, Huangwei, Introduction of Chinese Language Curriculum Resources Development and Utilization, China's Basic Education Network, 2002

[9] Fu Yihong, Choosing Varied Curriculum Resources to Develop New Ideas, Sohu Education Channel, 2002 
[10]Wang Su, Development and Utilization of History Curriculum Resources, China's Basic Education Network, 2001

[11]Xu Jicun, Discussion on the Curriculum Resources and Their Exploitation, Discipline Education, $2002(1)$

[12]Zhu Huang, Development and Utilization of History Curriculum Resources, Curriculum Teaching Material, 2002 (9) 